\title{
Using the Flipped Classroom Model to Improve Construction Engineering and Management Education
}

\section{Dr. Namhun Lee, Central Connecticut State University}

Dr. Namhun Lee is an associate professor in the department of Manufacturing and Construction Management at Central Connecticut State University, where he has been teaching Construction Graphics/Quantity Take-Off, CAD \& BIM Tools for Construction, Building Construction Systems, Building Construction Estimating, Heavy/Highway Construction Estimating, Construction Planning, and Construction Project Management. Dr. Lee's main research areas include Construction Informatics and Visual Analytics; Building Information Modeling (BIM), Information and Communication Technology (ICT) for construction management; and Interactive Educational Games and Simulations. E-mail: leen@ccsu.edu.

\section{Dr. Talat Salama P.E., Central Connecticut State University}

Dr. Talat Salama, PE, is an Associate Professor at the Department of Manufacturing and Construction Management. Before joining CCSU, he was an Associate Professor of Civil Engineering at the University of Alabama at Birmingham. Dr. Salama earned his BS and PhD in Civil Engineering and Structural Engineering, respectively, from Rutgers University and he earned his MS in Construction Engineering from the American University in Cairo. His expertise and research interests include Structural Health Monitoring of bridges using Non-Destructive Testing, and rehabilitation, retrofitting and strengthening of structures. He is a licensed Professional Engineer in the states on New Jersey and Alabama, with six years of industrial experience.

\section{Dr. Seong Jin Kim, Minnesota State University, Mankato}

Seong Jin Kim is a Ph. D. in Building Construction. He had diverse teaching experiences in K-16 settings. His primary interests in research are class environments in teaching and performance improvements based on the team work and team alignment in construction organizations and job sites. 


\section{Using the Flipped Classroom Model to Improve Construction Engineering and Management Education}

\section{INTRODUCTION}

Today's students are widely considered a technology savvy generation. They have grown up with technology including computers, the Internet, video games, mobile devices, and digital recorders. Due to this fact, it can be argued today's students are fundamentally different from previous generations in how they learn. ${ }^{1}$ They prefer instant response, simultaneous interaction, and constant communication within technology-enabled environments. ${ }^{2}$

Technology has played key roles in society. It has changed and will continue to change many aspects of how we live as well as how we communicate. Moreover, the notion of how people learn has been changing dramatically with the advent of technology. In fact, instructors currently use technology tools such as Blackboard, YouTube, Wiki, Google Drive, and Dropbox for their classes. Without a doubt, technology is changing the process of teaching and learning. Technology and education are considerably intertwined these days and many instructors have a few favorite technology tools for their teaching and connecting with students more easily and conveniently.

In a conventional teaching approach, instructors control the learning environment. Students are typically disciplined through the process of "assignment-study-recitation-test". 3 Under this paradigm, students are considered passive participants in the learning process. Students sit and listen to a series of lectures in classroom; study and complete assignments at home; and memorize and take tests at the end of a unit. This traditional approach encourages one-way communication. Hence, a conscious effort must be made for instructors to be aware of student problems and student understanding of content. In addition, the approach allows neither idiosyncratic student learning styles nor natural learning speeds. ${ }^{4}$ Students must put a considerable amount of unguided time outside of the classroom to understand and retain content knowledge.

Like many other students, construction engineering and management (CEM) students use mobile technology mostly for texting, gaming, and information searching in their daily life. They expect the same for their education. However, most higher education environments are contrary to this expectation. For students acquainted with technologies, the following question should be raised:

\section{"How can we improve student learning as well as the effectiveness of teaching in CEM education?"}

To address this question, it is necessary to identify an alternative pedagogical approach to delivering CEM courses efficiently. A surge of online educational sites provides instant access to huge resources of information, which easily lead to the extension of students' learning experience. ${ }^{5}$ Web technology has a large influence on alternative teaching paradigms. ${ }^{6}$ Most students, as long as they are motivated, can be self-directed and active learners with the support 
of technology in their learning process. Given these circumstances, the flipped classroom teaching model could become one of the most prevalent alternative approaches to facilitating student learning in CEM education.

In the flipped classroom model, the lecture and application modules of a course are reversed. The information element such as lecture is viewed outside of the designated class time by means of web-based informational videos, power point presentations, podcasts, and assigned readings. The comprehension and retention of this material is then assessed by means of quizzes or inclass discussions. The remainder of class time is given to the application modules, where the students apply the knowledge to hands-on activities, such as collaborative projects, interactive assessments, real world case studies, or student facilitated workshops, under the supervision of a faculty member.

\section{ISSUES OF THE TRADITIONAL LECTURE MODEL}

Traditional lecture models follow the Cartesian view of mind-matter dualism where the learner and the learning context are detached. ${ }^{7}$ The instructor determines the objectives, content, organization, pace, and direction of a lecture. Lecture is presented as a fixed, well-structured, and independent element. In traditional lecture models, learning activities are separated from their authentic context. Decontextualized knowledge is intrinsically frail as demonstrated by the students who are capable of recalling information on a test, but unable to apply the same concepts to different settings. ${ }^{8}$ These problems are not confined only to CEM education, but are shared in most higher education.

Traditional lecture models may lessen the opportunities for today's students to explore realworld problems. ${ }^{9}$ McCabe et al. ${ }^{10}$ state that current CEM courses mainly teach the theories of construction engineering and management. Thus, students may encounter difficulties in applying theoretical principles to authentic practices. Furthermore, AbouRizk and Sawhney ${ }^{11}$ assert that traditional lecture models are not fully capable of providing students with the necessary skills and knowledge to solve problems encountered in real world situations.

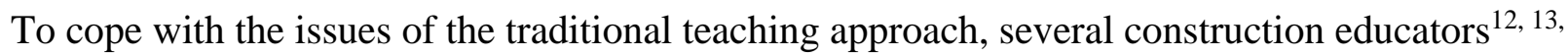
14,15 have made efforts at adding authentic learning activities in their courses through case studies and site visits. Moreover, Hegazy et al. ${ }^{16}$ emphasize that the hands-on approach is essential for CEM education. Even CEM students often mention the importance of hands-on exercises in their learning. Clearly, hands-on activities help to create more dynamic and stimulating learning experiences.

Students learn more when they are actively involved in their learning. Kinzie ${ }^{17}$ argues that students also benefit when they are engaged in the teaching and learning of their peers, such as group work, peer review, study groups, and peer teaching in and out of class. In the flipped classroom approach, lectures are delivered before class and concept mastery exercises are provided during class. This reversed teaching model also allows instructors to create a studentcentered learning environment and draw students' active engagement. For these reasons, the 
flipped classroom model is a proper pedagogical model to create active and collaborative learning environment for CEM students.

\section{RESEARCH OBJECTIVE AND METHOD}

The main objective of this study is to identify strategies for implementing the flipped classroom model in CEM education. To accomplish this objective, an extensive literature review was conducted to thoroughly examine the flipped classroom approach in higher education and observe pedagogical strategies to implement the reversed teaching method in CEM education. Based on this understanding, a plot study was carried out to investigate if the new teaching paradigm is more effective than the conventional teaching method.

For this study, students’ performance data on pre- and post-tests were collected from four different sections of an upper level construction estimating course. Two sections of the course used the traditional lecture model and the other two sections used the flipped classroom model to teach quantity surveying techniques for both "sitework" and "concrete" estimating. To analyze the data statistically, an independent sample t-test was used to check the effectiveness of instructional models. After analyzing the results of the pilot study, some pedagogical strategies for effective implementation of the flipped classroom model in CEM education were discussed.

\section{LITERATURE REVIEW ON FLIPPED CLASSROOM MODEL}

The flipped classroom model was developed over a twenty-five year period, matching innovation with available technology, beginning with Dr. Eric Mazur's Essence of Physics, a 1991 HyperCard program for Macintosh computers. ${ }^{18}$ The introduction of mainstream access to personal computers and the Internet in the late 1990s and early 2000s brought additional innovations in developing the association between student-centered instruction and educational technology. In 2000, Baker ${ }^{19}$ advocated the application of online instructional programs to free classroom time for collaborative learning and a shift in classroom pedagogy from teacher-led instruction to a student-centered model.

Learning Catalytics was first launched in 2011 to encourage student participation and collaboration through a cloud-based interactive education system. Learning Catalytics allows an instructor to create an open-ended question to any number of problems, graphs, images, video, or text. The students can respond to the question by mobile, home, or classroom computer. In addition, Learning Catalytics aggregates, analyzes, and displays the student responses, which actually allows the instructor to tailor interactive classroom time to students' needs. ${ }^{20}$

The transition from the traditional lecture model to the flipped classroom model begins with the creation of outside-of-class learning components including a series of instructional videos, podcasts, online readings, power point slides, and other online materials. Kolowich ${ }^{21}$ describes that the lecture videos or podcasts should be no more than thirty minutes in length, feature clear explanations and examples, and emphasize key concepts. In addition, students should be encouraged to actively participate in the learning process outside of the classroom. Bergmann 
and Sams ${ }^{22}$ suggest that students use the Cornell note-taking method in which they take notes, record any questions they have, and summarize their learning as a way for students to gauge their own initial understanding of the material.

Before starting the application portion of the module in class, it is necessary to assess student comprehension on outside-of-class learning components. This assessment is most commonly done through quizzes administered online or in class, web-based interactive discussion boards, or an open-ended, student-led discussion on the lecture topic in initial minutes of class time. Any misunderstandings or unclear material can then be addressed through additional examples or explanation. $^{20}$

In the flipped classroom approach, the instructor should use student-centered methods, not teacher-centered methods. The role of the instructor is changed to a more collaborative and cooperative contributor to the teaching process. The instructor assigns in-class activities, serves as a facilitator, and moves around the classroom to provide individual guidance and instant feedback. These activities should apply the knowledge gained through the video series or other outside assignments, and require more than just the repetition of outside-of-class learning. The successful flipped classroom relies heavily on the application of in-class activities to reach the higher levels of Bloom's Taxonomy and to make connections between the information acquired and the purpose or function of that information. ${ }^{23}$

A 2012 Educause article likened the flipped classroom to a workshop or "studio where students create, collaborate, and put into practice what they learned from the lectures they viewed outside class". ${ }^{24}$ In-class time is used for deeper engagement. Collaborative projects, individual or group problem solving exercises, or any other peer-based learning activities are given to enhance student understanding through differentiated instruction and hands-on experience. ${ }^{25}$

\section{Traditional Lecture}

Models

Focus on the transmission of knowledge in class

- The instructor prepares fixed, well-structured lecture and course materials to be delivered.

- Students are required to listen to lectures, ask questions, and take notes in class.

- Homework is assigned to demonstrate student understanding.

\section{Flipped Classroom}

Models

Focus on the application of knowledge in class

-The instructor prepares outside-of-class learning materials and in-class application modules.

-Students are required to watch or listen to outside-of-class learning compoenents before coming to class, communicating with peers and the instructor via online discussion.

- Class time is used for hands-on activities, while the instructor facilitates student engagement and understanding.

Figure 1. Traditional Lecture Models vs. Flipped Classroom Models 
The difference between traditional lecture models and flipped classroom models is summarized in Figure 1.

\section{DESIGN OF THE PILOT STUDY}

For this study, students’ performance data on pre- and post-tests were collected from four different sections of an upper level construction estimating course. Two sections of the course used the traditional lecture model and the other two sections used the flipped classroom model to teach quantity surveying techniques for both "sitework" and "concrete" estimating to investigate which approach is more effective than the other.

To examine the effect of the two pedagogical approaches to teaching construction estimating, seventy-seven undergraduate students were assigned at random to two groups: Group \#1 was taught using the traditional lecture model and Group \#2 was taught using the flipped classroom model. Participants included seventy-two males and five females, primarily juniors $(\mathrm{N}=36)$ and seniors $(\mathrm{N}=41)$. All of the participants were majoring in construction management.

In this study, the groups being compared were not assumed to be equivalent at the beginning of the study. Any differences observed at the end of the study might not have been caused by the intervention, but were due to pre-existing differences. Thus, this study included the nonequivalent control group design, where both control and experimental groups are pretested and posttested. All of the participants in the each group were required to take both the pretest and the posttest. The scores on each test ranged from 0 to 15.

$\begin{array}{llcl}\text { Control Group (\#1) } & \mathrm{P}_{1} & -- & \mathrm{P}_{2} \\ \text { Experimental Group (\#2) } & \mathrm{P}_{1} & \mathrm{I} & \mathrm{P}_{2}\end{array}$

$\mathrm{P}_{1}$ represents the pretest measure; $\mathrm{P}_{2}$ represents the posttest measure; I represents an intervention (the flipped classroom model), which means that experimental group students were taught from the flipped classroom model. On the other hand, control group students did not receive any treatment, which means they were taught from the traditional lecture model.

This research design involved measuring the dependent variable (i.e., students' conceptual understanding on content knowledge and students' ability in quantity takeoff) both before and after the intervention. The frequency distributions of the "change" score (also called a "gain" scores) of each group, which is the difference between the posttest score and the pretest score, were compared. In addition, a t-test was used to compare the means of the change scores of two independent samples and to test whether the differences between the change scores are statistically significant. Using this method, the error level can be kept at or below 5\%.

As described above, two instructional methods were tested: the traditional lecture model and the flipped classroom model. In this study, the independent variable is the instructional methods since they define the groups to be compared. The dependent variable is students' change scores whose means of the two groups are being compared. 
At the end of this study, the change scores of the students who were taught the course topics of "sitework" and "concrete" using the two instructional approaches were measured and compared to each other using a t-test. The ratio of the variance between groups to the variance within groups (also known as the "t-value") was used to assess whether there are significant differences in the mean scores of the two groups of students.

With the two groups, the null hypothesis $\left(\mathrm{H}_{0}\right)$ was stated as follows:

$H_{0:} \mu_{1}=\mu_{2}$, which means the means of the change scores of the two groups are statistically equal regardless of the two types of instructional methods.

This null hypothesis can be rejected if there is a statistically significant difference between the two means. Thus, the alternative hypothesis $\left(\mathrm{H}_{\mathrm{a}}\right)$ was:

$H_{a}: \mu_{1} \neq \mu_{2}$, which means there is a significant difference between the two means.

\section{DATA ANALYSIS AND RESULTS}

To determine the pre-existing differences, pretest scores in each group were first measured. Then, posttest scores were measured to identify the effect of the independent variable (i.e., the instructional methods). Table 1 shows descriptive statics for both pretest and posttest scores of the two groups. From this data, it appears that the use of the flipped classroom model produced a greater change in test scores. Table 2 lists the descriptive statistics for the change scores in each group. As shown in Table 2, the difference between the pretest means and posttest means of each group is 4.14 in group \#1 (the traditional lecture model) and 5.27 in group \#2 (the flipped classroom model).

Table 1. Descriptive Statistics for the Pretest and Posttest Scores

\begin{tabular}{l|cc|cc}
\hline & \multicolumn{2}{|c|}{ Group \#1 } & \multicolumn{2}{c}{ Group \#2 } \\
& Pretest & Posttest & Pretest & Posttest \\
\hline Range & $1-7$ & $3-14$ & $1-8$ & $4-15$ \\
Mean & 3.94 & 8.08 & 4.07 & 9.34 \\
S.D. & 0.32 & 0.50 & 0.28 & 0.47 \\
\hline
\end{tabular}

Table 2. Descriptive Statistics for the Change Scores

\begin{tabular}{lcc}
\hline & Group \#1 & Group \#2 \\
\hline Range & $1-8$ & $1-9$ \\
Mean & 4.14 & 5.27 \\
S.D. & 0.31 & 0.38 \\
\hline
\end{tabular}

Figure 2 illustrates frequency distributions in percentages, compared to the change scores, which represent the effects of the instructional methods. $27 \%(\mathrm{~N}=11)$ of students in group \#2 have a 
change score of 8 or more. Compared to this data, only 6\% $(\mathrm{N}=2)$ of students have the same in group \#1.

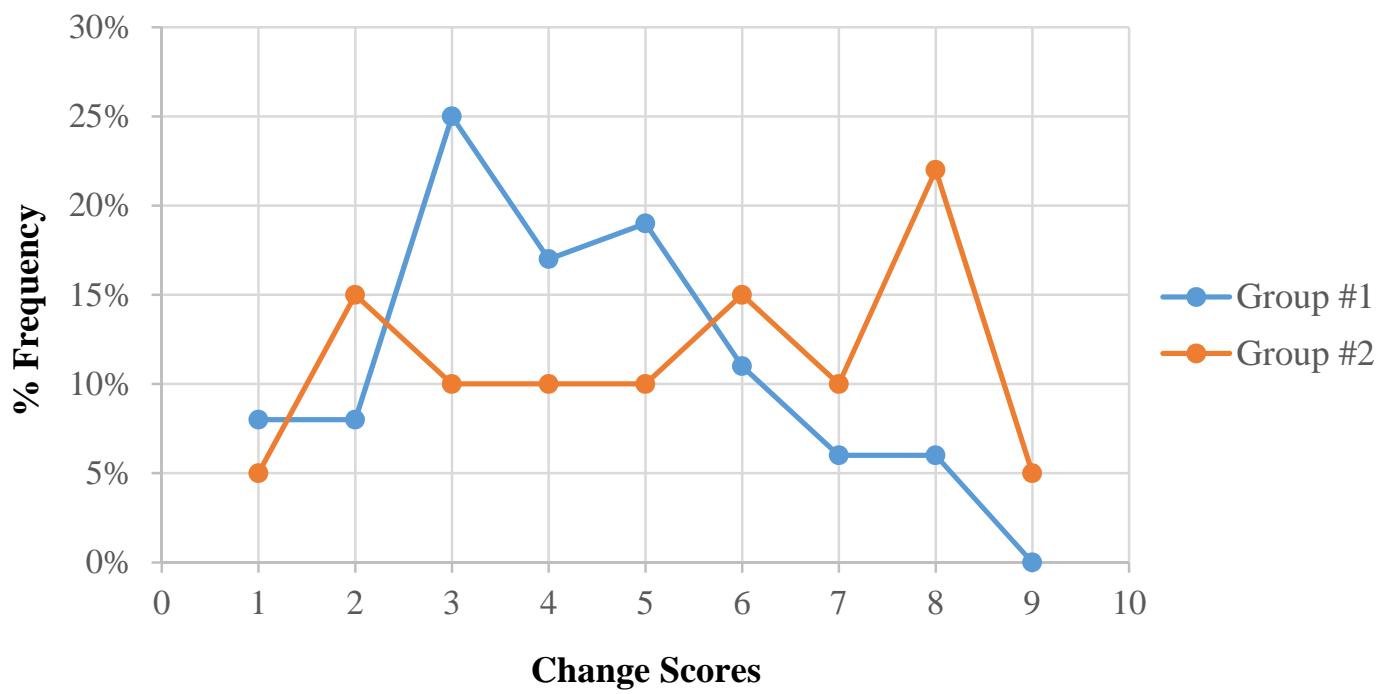

Figure 2. Frequency Distributions of the Change Scores

An independent-sample t-test was used to check the effectiveness of instructional models since it tests whether these differences are statistically significant or if they happened purely by chance. The numerical results of the t-test are summarized as:

$\begin{array}{lll}\text { df } & : & 74 \\ \text { t Stat } & : & -2.302 \\ \mathrm{P}(\mathrm{T}<=\text { t) two-tail } & : & 0.024 \\ \text { t Critical two-tail } & : & 1.993\end{array}$

The absolute value of the test statistic for this study is 2.302, which is greater than the corresponding critical value of 1.993. This results infer that there is statistically significant difference between the mean scores of the two groups of students at the $\mathrm{p}<0.05$ significance level. Therefore, the null hypothesis $\left(\mathrm{H}_{0}\right)$ was rejected in favor of the alternative hypothesis $\left(\mathrm{H}_{\mathrm{a}}\right)$. This indicates that the flipped classroom model does make a difference in the students' test performance.

\section{DISCUSSION AND CONCLUSION}

This study investigated which teaching approach is more effective than the other among the traditional lecture models and flipped classroom models with students' test scores. Based on the results of this pilot study, it is concluded that the flipped classroom approach can be effectively employed to provide CEM students with collaborative, interactive, adaptive, inquiry-based learning environments. However, for successful implementation of the flipped classroom model, two conditions must be satisfied: 
- The instructor should be able to adopt technology’s power to assist the students' learning process.

- The instructor should use student-centered methods, not teacher-centered methods. His or her role in classroom should be changed for a facilitator to create more collaborative and cooperative learning environments.

Unlike the traditional lecture model, the flipped classroom model encourages active student participation and strives for a student-centered environment in which student understanding is paramount, not the transfer of information. The use of pre-recorded lectures which can be viewed outside of class allows for a slower pace with information delivered in smaller segments. In the flipped classroom model, outside-of-class learning materials can be watched and reviewed as many times as necessary for students to understand the materials.

Before starting the application portion of the module, the use of in-class discussions provides an open forum to address any questions students have. ${ }^{24}$ During class time, peer-based hands-on activities are given to students not only to encourage collaboration amongst them but also to enhance student understanding of the information provided. When students work on the applied activity, the instructor should not only gauge student learning but also facilitate student engagement and understanding. The flipped classroom model can provide a great avenue for the instructor to gain a better insight into student difficulties and learning styles. ${ }^{26}$

The emphasis on hands-on activities also offers advantages over the traditional lecture model in terms of student comprehension and achievement. With the majority of class time devoted to the application of course materials, the course can be personalized to meet the individual needs of the student either by means of differentiated instruction for over or under performing students or through the use of activities designed to address various learning styles. ${ }^{27}$

By addressing the way of how today's students learn and creating student-centered learning environments, the instructor can create a drive to succeed as well as a sense of ownership within the students in regards to their own absorption of knowledge and the importance of that knowledge. In essence, Demski emphasizes that the driving motivation for learning becomes an intrinsic one rather than an extrinsic one. ${ }^{20}$

One of the greatest challenges to the successful implementation of the flipped classroom model is the added time and knowledge needed to prepare outside-of-class course materials. Unlike the traditional classroom, the flipped classroom requires the creation of outside-of-class learning components (e.g., lecture videos, podcasts, etc.), interactive measures of assessing student understandings (e.g., online quizzes, discussion boards, etc.), and complementary in-class activities or assignments that apply the knowledge gained. Therefore, instructors who are not familiar with video editing, podcasting, social media, or interactive technology would require training in these technical areas. This results in an added expense for the university and an additional time commitment by the instructor.

In addition to technological familiarity, the creation of a video or podcast series requires a level of comfort in front of the camera or microphone, and an ability to project enthusiasm and 
interest. Creating a lecture that is both engaging and informative may take a considerable amount of time and effort.

Beyond the technological difficulties and time constraints imposed by the creation of flipped model learning components, the true implementation of the flipped classroom model requires the participation of not only the instructor, but also the student. Removing the familiar aspects of the traditional lecture model can be a jarring experience for students. Adapting to such a drastic change will require a period of adjustment, and students may initially come to class unprepared and struggle with completing a hands-on activity in class. ${ }^{26}$ Additionally, some students may lack home access to the necessary technology, or struggle in an environment that relies on students to absorb knowledge through lecture without the benefit of being able to ask questions. ${ }^{27}$

In conclusion, the successful implementation of the flipped classroom model heavily hinges on available technology; university, instructor, and student collaboration; and a willingness, by all parties, to learn and adapt.

\section{Bibliography}

1. Bransford, J. D., Brown, A. L., \& Cocking, R. R. (Eds.). (1999). How People Learn: Brain, Mind, Experience, and School. Washington, D. C.: National Academy Press.

2. Lee, N. \& Rojas, E. (2010). "Innovative and Transformative Learning Environments in Construction Engineering and Management Education.” American Society for Engineering Education.

3. Beck, R. H. (2009). The Three R's Plus: What Today's Schools are Trying to Do and Why. U of Minnesota Press. pp. 3-6.

4. Pritchard, A. (2013). Ways of Learning: Learning Theories and Learning Styles in the Classroom. 3rd Edition, New York, Routledge.

5. Leasure, A. R., Davis, L., \& Thievon, S. L. (2000). "Comparison of Student Outcomes and Preferences in a Traditional vs. World Wide Web-based Baccalaureate Nursing Research Course.” Journal of Nursing Education, 39: 149-154.

6. Cole, R. A. (2000). Issues in Web-Based-Pedagogy: A Critical Primer. Westport, CT: Greenwood Press.

7. Barab, S. A., Hay, K. E., Barnett, M., \& Squire, K. (2001). "Constructing Virtual Worlds: Tracing the Historical Development of Learner Practices.” Cognition and Instruction, 19 (1), pp. 47-94.

8. Brown, J. S., Collins, A., \& Duguid, P. (1989). "Situated Cognition and the Culture of Learning.” Educational Researcher, 18 (1), pp. 32-42.

9. Lee, N. (2014). “A Conceptual Framework for Technology-Enhanced Problem-Based Learning in Construction Engineering and Management Education.” American Society for Engineering Education.

10. McCabe, B. Y., Ching, K. S., \& Savio, R. (2000). "STRATEGY: A Construction Simulation Environment.” ASCE Construction Congress VI, pp. 115-120. 
11. AbouRizk, S., \& Sawhney, A. (1994). "Simulation and Gaming in Construction Engineering Education.” American Society for Engineering Education.

12. Arslan, G. (2003) "Design of a Web-Based Virtual Construction Site Visit for Education of Civil Engineering Student (Part I).” Towards a Vision for Information Technology in Civil Engineering, pp. 1-8.

13. Chang, A., Du, S., \& Shen, F. (2012). “Engineer Self-Evaluation Checklist for Effective Site Visits.” J. Constr. Eng. Manage., 138(10), 1220-1229.

14. Delatte, N. (2005). “Case Studies for Civil Engineering Educators.” Structures Congress 2005, pp. 1-11.

15. Erdogan, B., Anumba, C., Bouchlaghem, D., \& Nielsen, Y. (2008). "Collaboration Environments for Construction: Implementation Case Studies.” J. Manage. Eng., 24(4), 234-244.

16. Hegazy, T., Abdel-Monem, M., Saad, D., \& Rashedi, R. (2013). "Hands-On Exercise for Enhancing Students' Construction Management Skills.” J. Constr. Eng. Manage., 139(9), 1135-1143.

17. Kinzie, J. (2005), Promoting Student Success: What Faculty Members Can Do (Occasional Paper No. 6). Indiana University Center for Postsecondary Research, Retrieved on January 15, 2016 from http://www.nsse.iub.edu/institute/documents/briefs/DEEP Practice Brief 6 What Faculty Members Can Do.pdf

18. Mazur, E. (1991). “Can We Teach Computers to Teach?” Computers in Physics. 31-38.

19. Baker, W. J. (2000). "The Classroom Flip: Using Web Course Management Tools to Become the Guide by the Side.” 11th International Conference on College Teaching and Learning, p.9-17.

20. Demski, J. (2013). Six Expert Tips for Flipping the Classroom. Campus Technology. 1-5. Retrieved on January 20, 2016 from http://campustechnology.com/articles/2013/01/23/6-expert-tips-for-flipping-the-classroom.aspx

21. Kolowich, S. (2011). Exploding the Lecture. Inside Higher Ed. Retrieved on January 22, 2016 from http://www.insidehighered.com/news/2011/11/15/professor-tries-improving-lectures-removing-them-class

22. Bergmann, J., \& Sams, A. (2012) Flip Your Classroom. $1^{\text {st }}$ edition, International Society for Technology in Education.

23. Krathwohl, D. R. (2002). "Revision of Bloom's Taxonomy: An Overview.” Theory Into Practice, 41(4), p.212218

24. Educause. (2012). Seven Things You Should Know About... Flipped Classrooms. Retrieved on January 20, 2016 from http://net.educause.edu/ir/library/pdf/eli7081.pdf

25. Rogers, T., \& Tingerthall, J. (2013). "Blended Learning and 'Flipping' the Construction Management Classroom for Improved Teaching and Learning." $49^{\text {th }}$ ASC Annual International Conference Proceedings.

26. Herreid, C., \& Schiller, N. (2013). "Case Studies and the Flipped Classroom.” Journal of College Science Teaching, 42 (5), 62-65.

27. Ropchan, K.., \& Stutt, G. (2013). Flipped Classroom. Retrieved on January 25, 2016 from http://etec.ctlt.ubc.ca/510wiki/Flipped_Classroom 